\title{
СОЩИОЛОГИЯ КУЯЬТУРОЛОГИЯ
}

DOI 10.22394/1818-4049-2017-80-3-79-86

УДК 347.1:34.03

\section{О. Р. Аверина \\ Н. М. Байков}

\section{Экстремистская симводика в интернет-пространстве как фактор угрозы социадизации мододежи}

B статье представлен социологический и культурологический анализ экстремистской символики, распространяемой славянским неоязиеством, представители которого используют свастичные символы в своих изданиях и на интернет-сайтах. Показано, ито псевдославянская идеология под благовиднъми предлогами зашиты древнеславянских корней, традииий и обрядов навязывает россиянам, прежде всего молодежи, человеконенавистнические идеи нацизма, их приемлемость и допустимость в современных условиях. Приведены результаты исследований, из которых видно, ито молодые люди являются наиболее активными пользователями интернет-ресурсов и соииальных сетей. Показано, ито экстремистская символика, тиражируемая в интернет-пространстве, представляет реальную угрозу соииализаиии молодежи и требует решительного противодействия со стороны государства и общества.

Ключевые слова: символ, символика, экстремизм, интернет-пространство, результаты соииологических и культурологических исследований, соииализаиия молодежи.

Вопросам социализации молодежи во все времена удемяется значительное внимание со стороны государства и общества. В современных условиях этот процесс в значительной мере детерминирован стремительным развитием интернет-технологий, которые радикально меняют не только материальный мир, но и сознание Аюдей. Международные угрозы терроризма и экстремиз- ма, масштабные фальсификации итогов Второй мировой войны, русофобия и другие современные реалии широко тиражируются с помощью интернетресурсов.

Интернет-пространство явцяется одним из ведущих факторов социализации молодежи. Молодые мюди проводят в Интернете значительную часть своего времени. Об этом свидетемьствуют дан-

Аверина Оцьга Рудомьфовна - канд. филос. наук, доцент кафедры философии, истории, государства и права, Дальневосточный институт управмения - филиал РАНХиГС (Хабаровск). E-mail: o_averina@mail.ru

Байков Николай Михайлович - д-р социол. наук, профессор, гмавный научный сотрудник научно-исследовательской маборатории, Дальневосточный институт управмения - филиам РАНХиГС (г. Хабаровск). E-mail: nmbaikov@rambler.ru 
ные социологических опросов момодежи в Хабаровском крае в режиме мониторинга ${ }^{1}$ (табц. 1).

Подавмяющее большинство молодых респондентов всех возрастных когорт посещают социальные сети, используют Интернет несколько раз в день. При этом 17-летние и 24-летние респонденты пребывают в виртуальном пространстве значительно больше времени, чем представители старшей возрастной группы (табц. 2).

Как свидетельствуют результаты опро- са, две трети пользователей интернетресурсов, социальных сетей считают своими основными целями не столько прагматические поисковые действия (работа в Интернете, поиск информации дияучебы, работы, пользование интернетмагазинами), скомько - информационнокоммуникативные (табл. 3). На знакомство с новостями и событиями, а также общение с мюдьми, друзьями, переписку в чатах уходит в среднем две трети времени пользователей Интернета и социальных сетей.

Таблииа 1

\section{Распределение ответов на вопрос: “Сколько времени Вы в среднем проводите в день в Интернете, соцнамьных сетях?" (2017 г.) (в \% от числа опрошенных) [1]}

\begin{tabular}{|l|r|r|r|r|}
\hline Варианты ответа & $\mathbf{1 7} \mathbf{\text { } е т ~}$ & \multicolumn{1}{|c|}{$\mathbf{2 4}$ года } & \multicolumn{1}{|c|}{$\mathbf{2 9} \mathbf{\text { } е т ~}$} & \multicolumn{1}{c|}{ Всего } \\
\hline Не нахожусь там & 1,1 & 1,2 & 1,3 & 1,2 \\
\hline Менее 1 часа & 10,2 & 12,4 & 17,6 & 13,2 \\
\hline От 1 до 2 часов & 17,8 & 18,6 & 29,7 & 21,8 \\
\hline От 2 до 3 часов & 27,3 & 27,5 & 23,0 & 26,0 \\
\hline От 3 до 5 часов & 23,6 & 17,8 & 15,1 & 19,0 \\
\hline Бомее 5 часов & 20,0 & 22,5 & 13,4 & 18,8 \\
\hline
\end{tabular}

Таблииа 2

Распределение ответов на вопрос: "Как часто в течение недени Вы посещаете соднальные сети, используете Интернет?" (2017 г.) (в \% от числа опротенньх) [1]

\begin{tabular}{|l|r|r|r|r|}
\hline Варианты ответа & $\mathbf{1 7}$ мет & 24 года & 29 мет & \multicolumn{1}{c|}{ Всего } \\
\hline Несколько раз в день & 81,7 & 82,0 & 72,0 & 78,8 \\
\hline 1 раз в день & 10,1 & 9,8 & 16,9 & 12,1 \\
\hline Несколько раз в неделю & 6,1 & 3,0 & 6,2 & 5,1 \\
\hline 1 раз в неделю & 0,4 & 3,0 & 1,2 & 1,5 \\
\hline Не пользуюсь & 1,8 & 2,3 & 3,7 & 2,5 \\
\hline
\end{tabular}

${ }^{1}$ Соииологический мониторинг "Молодёжь Хабаровского края: проблемы и перспекmивы" (1997 г., 2000 г., 2005 г., 2007 г., 2009 г. и 2013 г., 2017 г.) в разрезе трёх возрастных групп - 17, 24 и 29 лет. Опрошено от 550 до 700 респондентов. Тип выборочной совокупности - многоступенчатый, квотный в разрезе трёх основных характеристик (пол, возраст, территория проживания), случайный на этапе отбора респондентов. Научные руководители - д-р соииол. наук, проф. Н. М. Байков, канд. соииол. наук, дои. Ю. В. Березутский. 


\begin{abstract}
Распределенне ответов на вопрос: "С какнми основными делями вы пользуетесь интернет-ресурсами, соцнапьными сетями?" (2017 г.) Сумма ответов превышает $100 \%$, т. к. по методнке опроса можно бымо выбрать нескомько варнантов ответа [1]
\end{abstract}

\begin{tabular}{|c|c|c|c|c|}
\hline Варнанты ответа & 17 мет & 24 года & $29 \wedge е т$ & Всего \\
\hline $\begin{array}{l}\text { Знакомлюсь с новостями и событиями } \\
\text { в жизни общества }\end{array}$ & 60,4 & 65,8 & 64,1 & 63,4 \\
\hline $\begin{array}{l}\text { Общение с } \text { юдьми, друзьями, } \\
\text { переписка в чатах }\end{array}$ & 76,3 & 67,3 & 65,4 & 69,9 \\
\hline $\begin{array}{l}\text { Скачивание, просмотр фильмов, } \\
\text { телепередач, музыки }\end{array}$ & 52,2 & 47,7 & 41,5 & 47,4 \\
\hline Поиск информации для учебы, работы & 58,5 & 44,2 & 30,8 & 45,2 \\
\hline Работа в Интернете & 8,9 & 15,4 & 11,5 & 11,9 \\
\hline Пользуюсь интернет-магазинами & 26,3 & 29,2 & 30,3 & 28,5 \\
\hline $\begin{array}{l}\text { Создаю посты, выкмадываю размичные } \\
\text { материалы, фото }\end{array}$ & 17,4 & 24,6 & 17,9 & 20,0 \\
\hline Играю в игры & 29,0 & 20,4 & 17,5 & 22,5 \\
\hline Комментирую новости, события & 11,1 & 5,4 & 9,0 & 8,5 \\
\hline Другое & 0,4 & 0,4 & - & 0,2 \\
\hline
\end{tabular}

САедует подчеркнуть, что в Интернете можно обнаружить не только полезную информацию и завести безопасные знакомства. Среди молодых мюдей немало таких, которых привлекает нечто эпатажное, необычное, "крутое". Молодежь привлекают яркие "информационные обертки", в которьх зачастую упаковано то, что оказывает на "неокрепшие души" разрушитемьное воздействие.

В то же время, распространение противоправной информации является одним из видов преступиений в сфере информационнњ ресурсов. К этому относится и размещение в Интернете материалов экстремистского характера, в том числе запрещенной законом символики. Так, по данным Генеральной прокуратуры РФ, с 2013 г. число киберпреступлений увеличилось в шесть раз. При этом в 2016 г. две трети экстремистских преступлений было совершено в Интернете, причем каждое девятое - террористическое. За 3,5 года по требованию Генпрокуратуры России во внесудебном порядке заблокировали доступ к более чем 3 тыс. интернет-страниц, а с 50 тыс. ресурсов удалили противо- правную информацию [7].

Российское законодательство признает экстремизмом (экстремистской деятельностью) "...пропаганду и публичное демонстрирование нацистской атрибутики или символики мибо атрибутики или символики, сходных с нацистской атрибутикой или символикой до степени смешения" [1, ст. 1]. К символике такого рода относят так называемую древнеславянскую, или славяно-арийскую, символику, поскольку в основе ее межит свастика - символ, использовавшийся нацистской Германией в 1933 - 1945 гг.

Символ (от греч. sumballo - сбрасывать, сопоставмять, понимать) - закрепленный традицией знак, содержащий какую-либо информацию. Практически вся человеческая символика социальная и вКАючает символы самого раздичного содержания, относящиеся к социальным обшностям и социальным институтам мюбого уровня. Она отражает самые разнообразные стороны социальных отношений, включая социальные коммуникации. При этом каждый символ несет тройную нагрузку: информативную, ком- 
муникативную и консервативную [5].

Как социально-культурный знак, содержание символа представцяет собой идею, постигаемую феноменомогически. Содержание символа чаще всего невозможно адекватно передать вербальным способом, так как оно раскрывается через интуитивное соотнесение предметного образа и глубинного смысла.

Принципиальное отмичие символа от знака заключается в том, что смысл символа не указывает прямо на означаемый объект. Знак становится симвомом тогда, когда его употребцение предпомагает общезначимую реакцию не на сам символизируемый объект, а на отвлеченное значение или чаще целый спектр значений, конвенционально в той ими иной степени связываемых с этим объектом. Со свастикой в массовом сознании россиян связаны развязывание Второй мировой войны нацистской Германией и многомилиионные потери советских мюдей в Великой Отечественной войне, преступления против человечества, концмагеря, массовое уничтожение мюдей, агрессия и жестокость против мирного насемения, расистская и националистическая идеология.

Однако с середины 90-х гг. XX века в России стало распространяться славянское неоязычество, представители которого используют свастичные символы в своих изданиях и интернет-сайтах. Это разнородное движение, в основе которого межат идеи исторического и духовного первенства славян (славяноариев) по отношению $\mathrm{k}$ другим народам, возврата к политеизму - почитанию исконно русских богов и др. Последователями этой идеологии в России за последние четверть мет созданы десятки неоязыческих организаций, объединившихся в Союз славянских общин (г. Калуга, 1997 г.). При этом некоторые неоязыческие организации признаны судом экстремистскими и внесены в Федеральный перечень экстремистских организаций Министерства юстиции РФ, а их деятельность запрещена.

Тем не менее их представители напомняют интернет-пространство изображениями и текстами о "сакральном" значении свастичных символов. В качестве "Исконных" "древнеславянских" символов распространяются стилизованные разновидности свастики под вымышиенными названиями и сопровождаемые возникшей уже в наше время мифомогией. Например, символ, представляюший собой свастику красного цвета на белом фоне, позиционируется под названием "Фаш (Пиамень)" и трактуется как "... символ Защитного Обережного Духовного Огня. Сей Духовный Огонь очищает Дух человеческий от эгоизма и низменных помыслов. Это символ Мощи и Единства Воинского Духа, победы Светльх Сил Разума над силами Тьмы и невежества" [4].

Аналогичный символ, но с концами, загнутыми вмево, называется Агни. Утверждается, что это жславянский обережный символ Свяшенного огня жертвенника, земное воплощение бога Агни" [6]. Авторов не смущает, что Агни - бог индуистского, а не славянского пантеона. Но главное в том, что и "Фаш", и "Агни" однозначно схожи с нацистской симвомикой до степени смешения, сколько бы авторы текстов в Интернете ни утверждали, что эти "священные символы наших предков" не имеют ничего общего с нацизмом и фашизмом.

Увмечение псевдославянской символикой и мегковерие насемения дамо основание предприимчивым Аюдям наполнить интернет-рынок широким предложением различньг оберегов, талисманов и прочей продукции с разнообразными свастичными символами. Например, торговцы выставляют на продажу подвески с символами, поименованными как "Комядник" и "Аадинец", представАяющими собой фактически двойную свастику. Идеология псевдославянской симводики распространяет миф о том, что ж...древние славяне верили, ито оберегу покровительствовал воинственный u мудрый бог Коляда, которого современные обшественные деятели скорее назвали бы великим дипломатом, чем языческим идолом. Коляда владел искусством убеждения и мог договориться с кем угодно. Он также понимал, ито слово может ранить не хуже, чем отточенный меч и искусно "маневрировал", удерживая рубеж между мирными переговорами и кровопролитием. Колядник оберег, символизирующий судъбоносныеи позитивные перемены в судьбе, неизбеж- 
ную победу Добра над Злом, возрождение $\kappa$ новой жизни. Оберег, верили древние, изменяет судьбу сразу же, с пого самого момента, как его надели... Древние славяне сиитали, ито мальчики долхнь ноcumь этот оберег как атрибут настояшего мужчины с момента рождения" [3]. Все это сообщается мегковерной пубиике, разумеется, без всяких ссылок на источники. В серьезных научных исследованиях традиционной славянской кумьтуры и симвомики таких сведений не обнаруживается. Очевидно, что все это предназначено дия подрастающего покомения россиян. При этом используется высокая интернет-зависимость молодежи разных возрастов (табц. 1).

Искусственно созданный ажинотаж вокруг псевдославянской симвомики вынуждает правоохранительные органы выносить административные взыскания ее распространителям - мицам, которые размещают данные символы в сети Интернет, "репостят" их в социальных сетях и торгуют предметами с их изображением. Это подтверждается и резумьтатами опроса молодежи (табц. 4) Действия сотрудников правоохранитемьных органов по пресечению распространения псевдосмавянской симвомики вызывают протест у тех, кто увцекается неоязычеством. Они доказывают, что свастика была повсюду у древних славян, что запретить свастику - это значит оторвать народ от своих корней. Однако можно с большим основанием утверждать, что неоязычество не представияет собой возврат $\mathbf{K}$ аутентичным традициям предков. Неоязыческие тексты повествуют о событиях, о которых практически не сохранилось свидетельств, поэтому здесь открывается самое широкое поле дмя фантазий и новой мифологии. Отголоски дохристианской языческой кумьтуры никогда не исчезали из народной жизни, но все же непрерывной традиции, непосредственной преемственности с ней нет: ж... мы имеем дело не с некой унаследованной путем беспрерывной передачи от одних соииальных агентов $к$ другим системой отношений, а с иельм коналомератом сознательно реконструируемых и конструируемых взглядов, ритуалов, полемических тезисов, предметов культа и всего того, uто преврашиет группь достаточно в остальных отношениях обынных граждан в адептов новой верьн. [9, с. 6]

Апологеты свастики, выдавая ее за ведущий древнеславянский симво , приводят размичные аргументы в ее зашпту. Акцент демается на значении свастики, цвете, фоне, количестве и диине мучей, отходяшшх от основного перекрестья элементов. Исследователь истории сва-

Таблица 4

\section{Распределение ответов на вопрос "Сталкиваетесь ми Вы со следуюшими явАениями в сети Интернет, сопнальных сетях?" (2017 г.) (в \% от чнсаа опропенных)}

\begin{tabular}{|c|c|c|c|c|c|c|c|c|}
\hline \multirow[b]{2}{*}{ Варианты ответа } & \multicolumn{2}{|c|}{17 мет } & \multicolumn{2}{|c|}{24 года } & \multicolumn{2}{|c|}{29 цет } & \multicolumn{2}{|c|}{ Всего } \\
\hline & 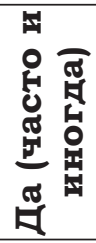 & 哭 & 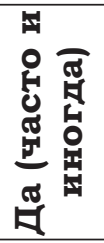 & 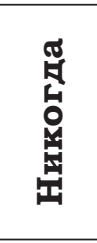 & 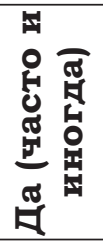 & 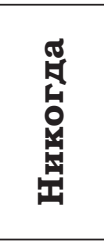 & 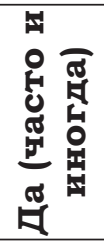 & 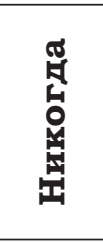 \\
\hline $\begin{array}{l}\text { Оскорбления, угрозы и } \\
\text { унижение }\end{array}$ & 69,3 & 30,7 & 72,2 & 27,8 & 63,1 & 36,9 & 68,4 & 31,6 \\
\hline Пропаганда насилия & 52,6 & 47,4 & 42,9 & 57,1 & 51,6 & 48,4 & 49,0 & 51.0 \\
\hline $\begin{array}{l}\text { Призывы на возбуждение } \\
\text { ненависти, вражды к } \\
\text { представителям разных } \\
\text { национальностей, религий }\end{array}$ & 48,5 & 51,5 & 42,2 & 57,8 & 44,0 & 56,0 & 45,0 & 55,0 \\
\hline Терроризм, экстремизм & 41,3 & 58,7 & 39,1 & 60,9 & 40,9 & 59,1 & 40,5 & 59,5 \\
\hline
\end{tabular}


стики Р. Багдасаров считает, что «... под опредемение нацистской символики может подходить мишь свастика, стоящая на ребре в $45^{\circ}$, с концами направменными в правую сторону. Именно такой знак находияся на государственном знамени Национал-социалистической партии Германии с 1933 по 1945 гг., а также на эмблемах гражданских и военных служб этой страны. Автор указывает, что следует называть данный символ не "свастика", a Hakenkreuz (буквально - крюкокрест), как поступали сами нацисты [2].

По нашему мнению, традиционная свастика и ее вариации имеют ту же конфигурацию, что и Hakenkreuz: две перекрещенные под прямым угмом минии, окончания которьх загнуты под прямьм угАом Аибо вправо, мибо влево, т. е. сходны с нацисткой свастикой до степени смешения. Например, символы под названиями "Посомонь" и "Чароврат" представляют собой ту же свастику, стоящую на ребре в 45 градусов, но красного цвета и с более короткими концами. В тонкостях цвета, фона и значения разбираются заинтересованные мица, а широкая пубцика видит то, чем данные изображения явАяются - фашистскую свастику.

В этой связи примечателен комментарий пользователя одного из интернетфорумов: "Я настаиваю - свастика может зазвучать солярным мифом или причастностью $\kappa$ круговращению сансары только для специалистов. Для всех остальных свастика воплотилась в середине XX века в виде символа немецкого наиизма. Это горький опьт. ...Глупа попытка внедрить свастику в сознание, отлучив ее от нацистского прошлого. ...Мне, простолу обывателю, горько видеть символ бесчеловечности. От которого вполне можно отказаться. Неужели нет ни капли рассудка? А если рассудок присутствует, позволю себе предположить и умысел.

Псевдославянская символика неразрывно связана с неоязыческой идеей исторического первенства славян (славяноариев), превосходства славян над неславянами, язычества - над другими религиями. Это подтверждают и резумьтаты многих религиоведческих экспертиз экстремистской символики. Так, например, объектом анализа при проведении одной из экспертиз являлось интернетизображение, в центре которого в желточерной цветовой гамме, характерной дАя моготипа компании сотовой связи "Бимайн", размещался символ "коловрат", наиболее популярный $\mathrm{y}$ неоязычников (двойная свастика с концами, загнутыми вправо, по часовой стрелке, и напоминаюшими мезвие косы). В верхней части изображения располагалась фигура человека с воздетыми кверху руками, падающего навзничь, кричащего: "Ааааа..." и скошенного цезвиями "коловрата". Под изображением размещена надпись "Дуй из России" и текст: "Специальное предложение для неруси: ТАРИФ "ДОМАШНИЙ»! (Говорить будешь ДОМА»).

Характеризуя идеомогию неоязьчества, историк В. Шнирельман пишет: "...в ux лексике отсутствует термин меловечествон. Зато они оперируют понятиями "рода", "народа" и "рась", вынося остальную часть человечества за скоб$\kappa и$. Все другие для них - нечто низшее, или, во всяком случае, абсолютно муждоен... Примечательно, ито грандиозный мифо орошлом, создаваемыйязыческими идеологами, повествует только о ирусских, "славянах" или "арийиах". И, хотя эти герои совершают путешествия, опоясываюшие едва ли не весь земной шар, достойного места для других народов в этой картине мира, как правило, не находитсяи [8, с. 1]. Ученый также отмечает, что посредством неоязыческой публицистической и художественной митературы постепенно осуществлялась реабилитация свастики. В поисках "исконной русской веры" идеологи неоязычества создали целый ряд мифомогических кАише. К таковым можно отнести, например, "Правь". Они заявляют, что они истинно православные, ибо славят Правь - светлый мир языческих богов. "Они, по сути, повторяли путь австрийских ариософов и германских неоязычни-

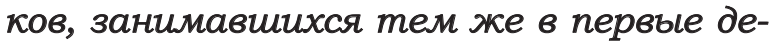
сятилетия $X X$ в. и создавиих символику и ритуалы, с благодарностью воспринятые наиистами" [8, с. 7].

Очевидно, что доступность псевдославянской символики в различных вариантах в интернет-пространстве преследует цель внушить пользователям, прежде всего молодежи, мысли о том, что она от- 
ражает наши корневые славянские представиения о Сомнце, свете, жизни и добре. В дамьнейшем становится возможным и признание нацизма в качестве нормы и как следствие - появмение на странич-

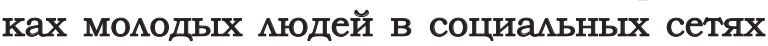
постеров с изображением нацистской симвоцики и атрибутики (нацистского фиага, "момний СС" и собственно свастики) в привцекательном контексте. Среди них встречались, например, такие: восходящее солнце в виде свастики в конфигурации Hakenkreuz; изображение нацистского знамени (красное полотнище со свастикой черного цвета, вписанной в бемый круг) с подписью «Сомнышко всходитн; рисунки в стиме японской анимации, изображающие юных девушек на фоне нацистского фмага, с нацистскими повязками на рукавах и т. д. Поражают названия групп в социальных сетях: "Адомьф Гитмер", "В нацизме_юмор", "В нацизме_няши" ${ }^{2}$.

Современная ситуация такова, что социамьные сети - это многомимиионные виртуамьные сообщества, вмияющие на сознание и поведение момодежи. Это подтверждают и громкие события последних мет - от несанкционированных митингов до террористических и экстремистских актов с участием молодых мюдей. С этих позиций можно поддержать предиожения тех экспертов, которые предлагают в целях общественной безопасности ввести принцип погомовной верификации пользователей с 14 мет, т. е. с момента получения гражданином паспорта. Верификация и строгий контроль за подиинностью имен мишь усилит ценность собственного мнения и виртуамьного общения. Кроме того, привязка аккаунта к паспорту поможет ре- шить проблему манипумяции общественным мнением в интернет-пространстве, сократит возможности дия распространения всевозможных псевдославянских образчиков нацистской симвомики.

\section{Список литературы:}

1. Федеральныйзакон "О противодействии экстренистской деятельности: от 25.07.2002 № 114-Ф3 [Электронный ресурс]. URL: base. garant.ru/12127578/

2. Багдасаров P. В. Свастика: священный символ. Этнорелигиоведческие очерки [Электронный ресурс]. М. : Белые Альвы, 2006. URL: http://bagdasarovr.narod.ru/swastika. htm\# putyami

3. Браславская И. Колядник (оберег): значение и фото [Электронный ресурс]. URL: http://fb.ru/article/268888/kolyadnik-oberegznachenie-i-foto

4. Обереги славян - Соларные (свастичные) символы [Электронный ресурс]. URL: http://derzhavarus.ru/solyarnye-svastichnyesimvoly. $h t m l$

5. Символика сочиальная Юлектронный pecypc]. URL: http://ponjatija.ru/node/ 10507

6. Славянская культура Гэлектронный pecypc]. URL: http://slavyanskaya-kultura.ru/ slavic/symbol/slavjanskii-simvol-agni.html

7. Чайка заявил о шестикратном росте иисла киберпреступлений с 2013 г. [Электронный pecypc]. URL: http://www.rbc.ru/rbcfreenew s/599e9d289a79470ea5767903

8. Шнирельман В. Русское родноверие. Неоязиество и национализм в современной России [Электронный ресурс]. M., 2012. URL: https://bookz.ru/authors/viktor-6nirel_man/ russkoe-_439/1-russkoe-_439.html

9. Пщеглов А. М. Возврашение богов: политическая сочиология неоязычества. М. : Издательство "Пробел", 1999. - 19 с.

\section{Библиографическое описание статьи}

Аверина О. Р., Байков Н. М. Экстремистская символика в интернет-пространстве как фактор угрозы социализации молодежи // Власть и управцение на Востоке России. 2017. № 3 (80). С.89-96. DOI 10.22394/1818-4049-2017-80-3-79-86

\footnotetext{
2Значение слова "няша" в современной молодежной субкультуре таково. Японские аниматоры при создании мультипликаиионных фильмов использовали междометия на японском языке "ня", ито соответствует русскому "мяу". "Няша", "няшная" употребляется в значении "миловидное создание, вызываюшее милые чувства, при виде которого хочется сказать "мяу". Синонимы: "милашка", "душка" и т. п.
} 


\section{O. R. Averina \\ N. M. Baykov}

\section{Extremist symbols in the internet as a factor of the threat of youth' socialization}

The article presents sociological and culturological analysis of the extremist symbolism spread by the Slavonic neopaganism, whose representatives use swastika symbols in their editions and on Internet sites. It is shown that the pseudo-Slavic ideology, under the pretexts of protecting ancient Slavonic roots, traditions and rituals, imposes on the Russians, first of all young people, the misanthropic ideas of Nazism, their acceptability and admissibility in the modern conditions. Based on the results of research it is shown that the extremist symbolism, replicated in the Internet space, represents a real threat to the socialization of young people and requires resolute opposition from the state and society.

Keywords: symbol, symbolism, extremism, Internet space, results of sociological and cultural studies, socialization of youth.

\section{References:}

1. Federal'nyj zakon "O protivodejstvii ehkstremistskoj deyatel'nostiw ot 25.07.2002 № 114-FZ [EHlektronnyj resurs]. URL: base.garant. $\mathrm{ru} / 12127578 /$

2. Bagdasarov $R . \quad V$. Suastika: suyashchennyj simvol. EHtnoreligiovedcheskie ocherki [EHektronnyj resurs]. M. : Belye Al'vy, 2006. URL: http://bagdasarovr.narod.ru/ swastika.htm\#putyami

3. Braslauskaya I. Kolyadnik (obereg): znachenie $i$ foto [EHlektronnyj resurs]. URL: http://fb.ru/article/268888/kolyadnik-oberegznachenie-i-foto

4. Oberegislavyan-Solyarnye (svastichnye) simvoly [EHlektronnyj resurs]. URL: http:// derzhavarus.ru/solyarnye-svastichnye- simvoly.html

5. Simvolika social'naya [EHlektronnyj resurs]. URL: http://ponjatija.ru/node/10507

6. Slavyanskaya kul'tura [EHlektronnyj resurs]. URL: http://slavyanskaya-kultura.ru/ slavic/symbol/slavjanskii-simvol-agni.html

7. CHajka zayavil o shestikratnom roste chisla kiberprestuplenij s $2013 \mathrm{~g}$. [EHlektronnyj resurs]. URL: http://www.rbc.ru/rbcfreenews/5 99e9d289a79470ea5767903

8. SHnirel'man $V$. Russkoe rodnoverie. Neoyazychestuo $i$ nacionalizm v sovremennoj Rossii [EHlektronnyj resurs]. M., 2012. URL: https://bookz.ru/authors/viktor-6nirel_man/ russkoe-_439/1-russkoe-_439.html

9. SHCHeglov A. M. Vozvrashchenie bogov: politicheskaya sociologiya neoyazychestva. $M$. : Izdatel'stvo "Probel", 1999. - 19 s.

\section{Reference to the article}

Averina O. R., Baykov N. M. Extremist symbols in the internet as a factor of the threat of youth' socialization // Power and Administration in the East of Russia. 2017. No. 3 (80). PP. 89-96 DOI 10.22394/1818-4049-2017-80-3-79-86

Averina Olga Rudolfovna - Candidate of Philosophy, associate professor of the philosophy, history, state and right chair, the Far-Eastern institute of management branch of RANEPA (Khabarovsk).E-mail: o_averina@mail.ru

Baykov Nikolay Mikhaylovich - Doctor of Sociology, professor, chief researcher of the research laboratory, the Far-Eastern institute of management - branch of RANEPA (Khabarovsk).E-mail: nmbaikov@rambler.ru 